\title{
ADVANCED PRIMARY ABDOMINAL PREGNANCY - A CASE SERIES FROM A REMOTE RURAL HOSPITAL IN NORTHEAST INDIA
}

Carolin Solomi $^{1}$, Vijay Anand Ismavel ${ }^{1}$, and Ann Miriam ${ }^{1}$

${ }^{1}$ Makunda Christian Leprosy and General Hospital

April 28, 2020

\section{Hosted file}

Advanced Primary Abdominal Pregnancy Manuscript.doc available at https://authorea.com/users/ 308012/articles/439002-advanced-primary-abdominal-pregnancy-a-case-series-from-a-remote-ruralhospital-in-northeast-india 